\title{
Geloofsgroei by Paulus?
}

\author{
GMM Pelser
}

\section{Abstract}

In this essay the question is posed as to whether Paul viewed faith as essentially an entity that can grow or increase within the believer or is given by God in different degrees to different people. The investigation is limited to $\mathrm{Rm} 12: 3 ; 14: 1 ; 2$ Cor $10: 15$; Phlp $1: 25$ and 1 Th $3: 10$. The conclusion is reached that as far as these passages are concerned, the answer to the question is negative, with the possible exception of 2 Cor 10:15. It seems therefore that according to Paul, faith is faith, nothing less and nothing more. In so far, however, as there is mention in Paul of growth connected with faith, it concerns the believer's answer to the imperative in the indicative by living up daily (and increasingly) to his faith. Essentially faith cannot be weak or mediocre. If this should be the case, it is not faith any more.

Die oogmerk van hierdie studie is om ' $n$ antwoord te probeer vind op die vraag of Paulus van oortuiging was dat geloof ' $n$ entiteit is wat nie alleen in verskillende mate aan individuele gelowiges geskenk word nie, maar ook van so 'n aard is dat dit kan groei of toeneem. Kan ons gelowiges dus in kategoriee of stadia van gelowigheid indeel en almal terselfdertyd as gelowiges beskou? Of kan daar alleen van geloof of ongeloof sprake wees?

'n Vraag soos hierdie klink by die eerste aanhoor daarvan nie slegs vreemd nie, ook die antwoord daarop blyk voor-die-hand-liggend te wees. Moet dit naamlik nie as aksiomaties beskou word dat ook die mens, soos die lewende werklikheid rondom hom, nie net liggaamlik nie, maar veral verstandelik en geestelik groei en ontwikkel nie? Berus die hele besig wees met opvoeding en onderwys nie juis op die feit dat die mens ' $n$ wese is wat deur ervaring en onderrig bykans onbeperk kan leer en ontwikkel nie? Geld dieselfde nie ook op die religieuse terrein nie, en is die kerklike verkondiging in al sy gestaltes nie juis daarop gerig om geloof te wek en te laat toeneem nie?

Argumente soos hierdie klink baie oortuigend en aanvaarbaar en tog klink iets nie pluis nie. Kan geloof sonder meer gelykgestel word aan natuurlike of biologiese prosesse? Is dit nie 'n entiteit wat in 'n bepaalde sin extra nos en sui generis is nie? Is geloof deelbaar, kategoriseerbaar, ontwikkelbaar of intensiveerbaar? Of is geloof gewoon geloof en niks minder en niks meer nie? 
Die antwoord op hierdie vrae hang ten dele af van die vraag òf geloof volledig gawe is ò ook alleen menslike beslissing. Ek sê ten dele, omdat selfs al sou dit volledig gawe wees, daar nog die vraag kan bestaan of dit in ' $n$ mindere mate aan sommige mense en in ' $n$ meerdere mate aan ander geskenk word. Dit lyk of daar konsensus is dat daar met betrekking tot die Pauliniese geloofsbeskouing primêr gedink moet word aan geloof as gawe, en dat minstens onderskei moet word tussen die fenomeen geloof as sodanig en geloof as daad. In hierdie verband kan met vrug na'n paar wyses van onderskeiding gekyk word. Lohmeyer (1929) onderskei tussen geloof as metafisiese prinsipe en geloof as daad. As metafisiese prinsipe is dit nie alleen die geloof wat Christus gehad het of gee nie, maar veral wat Hy self is. Dit is net so openbaring as wat Christus is, en net soos Christus deur God geskenk. As daad is geloof die historiese verwerkliking van geloof as prinsipe en dit kom tot uiting in kennis en gehoorsaamheid. Hierdie kennis en gehoorsaamheid is egter ook nie meer daad van die gelowige nie, maar die werking van die prinsipe, vrug van die Gees. Binder (1968: 11-13) gaan nog verder. Op grond van 'n uitspraak soos in Galasiërs 3:23,25 beskou hy geloof by Paulus as ' $n$ van-God-komende transsubjektiewe, bo-subjektiewe entiteit. Dit is nie ' $n$ psigologiese fenomeen wat hom in die individu voltrek nie. Dit is ' $n$ heilswerklikheid, die nuwe verbond wat onafhanklik van die mens bestaan, 'n gebied waartoe die mens slegs kan toetree. Omdat die geloof onafhanklik van die mens bestaan, hoef die mens nie eers genoem te word wanneer oor geloof gepraat word nie. Hoewel Friedrich hom nie heeltemal met hierdie beskouing kan vereenselwig nie, maak ook hy 'n stelling wat baie naby hieraan kom: 'Glaube ist in der Tat nicht eine Gemütstimmung des Menschen, ein psygischer Affekt oder eine subjektive Qualität des Menschen' (Friedrich 1982: 98). Terwyl 'n mens met Friedrich moet saamstem dat geloof nie as gemoedstemming of psigologiese affek gedefinieer kan word nie, bly die vraag egter nog bestaan na die aard van die mens se betrokkenheid en rol by die saak.

Ook Neugebauer (1961: 157-159) lê sterk klem op geloof as 'n vanbuite-gegewe realiteit. Ook hy sien geloof by Paulus byna uitsluitlik as heilsgebeure, as indikatief wat deur God in Christus geskenk is. Die geloof het gekom en is geopenbaar. Paulus roep niemand op om te glo nie; al wat van die mens gevra word, is om in die geloof te lewe. 'Er hat nie das gläubige Tun und das gläubige Verhalten als pistis oder pisteuein bezeichnet, denn er konnte das Heilsgeschehen des Glaubens nie zur Aufgabe des Menschen machen' (1961: 169). Paulus het geweet 
dat uit die geloof die werk moes volg, dat die geloof histories in die liefde werksaam moes wees, maar hy kon hierdie doen self nie 'geloof' noem nie.

Dit is bekend dat ook Bultmann (1968: 315-316) bepaalde onderskeidings met betrekking tot geloof by Paulus getref het. Hy onderskei tussen die struktuur van die geloof en die lewe in die geloof, ' $n$ onderskeiding wat met reg getipeer kan word as verwysend na die eksistensiale en eksistensiële of ontologiese en ontiese dimensies van geloof (so byvoorbeeld Neugebauer 1961: 159). Ook Bultmann erken die gawekarakter van geloof. Gesien uit die gesigspunt van die mens is geloof vir hom wel 'n wilsdaad, 'n beslissing om die uitnodiging van God te aanvaar. Maar gesien uit die gesigspunt van geloof, is geloof ' $n$ geskenk van God (1965: 53). Tog ken Bultmann aan die rol wat die mens in die geloof speel, 'n meer prominente plek toe as die hierbo genoem, iets waarvoor hy dan ook deur Neugebauer gekritiseer word (kyk Neugebauer 1961: 157-159). Hoewel geloof dus vir Bultmann voluit 'n geskenk is, kan dit nie buite die 'Entscheidung' van die mens om geskenk wees nie. 'Denn der Glaubende kann seine Entscheidung da er ihre Mögligkeit als Gnade erfährt, nur als Geschenk der Gnade selbst verstehen - aber eben gerade seine Entscheidung! - den ein Glaube, der von Gott ausserhalb der Entscheidung des Menschen gewirkt ist, wäre offenbar kein echter Gehorsam' (1968: 330). Geloof is Godgewerk in soverre as wat die voorafgaande genade die menslike beslissing moontlik maak, sonder dat geloof daarmee sy 'Entscheidungscharakter' verloor (1968: 330-331).

Het hierdie beskouinge oor geloof by Paulus nou vir ons enige lig laat opgaan met betrekking tot ons vraag? Ek glo nie veel nie. Behalwe dat wanneer geloof soos deur Binder en selfs Neugebauer as so ' $n$ van die mens en menslike beslissing onafhanklike entiteit beskou kan word, 'n mens inderdaad kan sê dat sprake van geloofsgroei prinsipieel uitgesluit is. ' $n$ Mens sou dan hoogstens kon vra of die intrede in hierdie werklikheid met verdrag kan verloop of 'n eenmalige, volledige gebeurtenis is. Dit bring ons terug by ons oorspronklike vraag, naamlik wat Paulus van die saak sê.

Dit is merkwaardig dat, terwyl Paulus blykbaar tog een en ander oor die saak te sê het, die oorgrote meerderheid Nuwe-Testamentici wat hulle hand aan 'n Pauliniese teologie gewaag het, soos die graf oor hierdie saak swyg (so byvoorbeeld Richardson, Ridderbos, Goppelt, Eichholz, Kümmel, Bornkamm, Lohse). In die enkele gevalle waar daar wel na die moontlike tersaaklike uitsprake by Paulus verwys word, 
word dit eintlik slegs in die verbygaan gedoen (so byvoorbeeld by Bultmann en Conzelmann). In kommentare is dit uit die aard van die saak anders, maar ook hiér word nie veel oor die kwessie gehandel nie. Waarom die stilswye? Is die saak te vanselfsprekend of is dit nie van belang nie? Conzelmann (1968: 193) maak die opmerking dat geloof natuurlik ook 'n persoonlike kant het (met verwysing na Rom 12:3; 14:1; 2 Kor 10:15) en voeg dan daaraan toe: 'Aber die Erfahrung, die man mit dem Glauben macht, wird nicht zum inhalt der Botschaft .... Man wird nicht sellig durch starken Glauben sondern durch Glauben.'

In die ondersoek wat hieronder volg, gaan nie gekyk word na alle uitsprake wat moontlik in aanmerking geneem kan word nie, maar slegs na dié waarna daar gewoonlik verwys word wanneer geloofsgroei of -toename, of grade van geloof ter sprake gebring word.

\section{Romeine 12:3 (metron pisteōs)}

Uit die geskiedenis van die interpretasie van hierdie teks blyk duidelik dat die menings van eksegete van die vroegste tye af aansienlik uiteenlopend was (kyk Cranfield 1962: 345-351). Die belangrikste eksegetiese kwessie wat hier om 'n beslissing vra, is of die genitief pisteōs as partitief of as apposisie gelees moet word. Die meeste kies vir partitief, maar interpreteer dan nogtans verskillend: of as fides qua soos dit aan elke gelowige afsonderlik toebedeel is (Schlier 1979: 367; Althaus 1970: 126) ò as wonderwerkende krag (Barrett 1977: 235) ò as bepaalde toebedeelde garisma (Ridderbos 1959: 276; Michel 1963: 296-297); Käsemann 1974: 324). Word die genitief as apposisie gelees (soos byvoorbeeld Wilckens 1982: 11-12), word daaraan die betekenis geheg van geloof as norm waarvolgens die beoefening van garismata beoordeel moet word.

Daar is nie twyfel nie dat Romeine 12:2-8 parallel is aan 1 Korintiërs 12:4-6 en dat Efesiërs 4:7 (Heni de hekastō hèmōn edothē hè charis kata to metron tês dōreas tou Christou) seker die beste interpreterende ekwivalent van Romeine 12:3 is. Soos in 1 Korintiërs 12:4-6 word ook hiér (Rom 12:3) gehandel oor die eenheid en verskeidenheid van die kerk as liggaam van Christus en oor die bestaan en die beoefening van die verskillende garismata. In die gang van die argument in die perikoop word die verskillende onderdele so aan mekaar gebind (kathaper gar vs 4; echontes de vs 6), dat dit duidelik is dat die beroep op die lesers dat niemand van homself meer moet dink as wat sy metron pisteōs hom toelaat nie, ten nouste saamhang met die verskeidenheid van garismata en die vereistes wat vir die beoefening daarvan gestel word. Soos deur 
die analogie van die liggaam tot uitdrukking gebring word, gaan dit in die perikoop nie slegs om die eenheid van die lede in die liggaam nie, maar juis ook daarom dat elkeen sy eie funksie (praxis vs 5) moet vervul sonder om daardeur die eenheid te versteur deur hom bo ander te verhef. Wat wil metron pisteōs dan in hierdie konteks sê? Dit hou sonder twyfel verband met die onderskeie garismata wat aan elkeen in die gemeente toebedeel is en wil spesifiek die riglyne neerlê vir die gesindheid wat elke gelowige met betrekking tot sy eie garisma en in verhouding tot sy mede-gelowiges behoort te openbaar. Dit beteken dat hy nie meer van homself moet dink as wat die grense of belangrikheid van sy besondere garisma hom toelaat nie. Hy moet nie maak asof sy funksie of bydrae in die gemeente belangriker is as die van ander nie (vgl 2 Kor 10:13). Hy moet nie probeer uitgryp bo wat aan hom toegewys is nie (so tereg Käsemann 1974: 320). In hierdie konteks het metron pisteōs dus beslis nie te make met die graad van fides qua wat aan elkeen toebedeel is nie, maar is dit in 'n sekere sin sinoniem met garisma.

\section{Romeine 14:1 (asthenōn tē pistei)}

Die lê voor die hand dat die uitdrukking 'swakkes in die geloof' nie 'n karakteristiek weerspieël wat die groep mense waarna dit verwys, aan hulleself toegeken het as uitdrukking van hulle selfverstaan nie. Dit is klaarblyklik 'n betiteling wat gekom het van die kant van die sogenaamde sterkes (so tereg Wilckens 1982: 81; Schlier 1979: 403 e a). Dit is verder duidelik dat Paulus hom vir die doeleindes van sy argumentasie by hierdie spraakgebruik aansluit, wat egter nie beteken dat hy hom noodwendig met hierdie benaminge vereenselwig het nie. Dit verg ook nie veel eksegetiese insig om by die lees van die res van die perikoop agter te kom waarop hierdie uitdrukking of benaming betrekking gehad het nie. Dit het duidelik nie gegaan oor 'n swak of gebrekkige fides qua by hierdie mense nie, maar om ' $n$ bepaalde beskouing by hulle in verband met die implikasies en konsekwensies van die geloof. Dat hulle deur die sogenaamde sterkes as swak in die geloof bestempel is, berus klaarblyklik daarop dat hulle gesien is as mense wat nie die innerlike krag gehad het om hulleself volkome vry te voel in die vryheid waarmee Christus hulle van die afgode vrygemaak het nie en hulle ook nie in vryheid volkome kon losmaak van die Joodse godsdienstige kalender en gebruike nie. Soos die sterkes hierdie geloofshouding as ' $n$ teken van swakheid beskou het, so het die swakkes weer hulle bedenkinge gehad oor die wyse waarop die sterkes die implika- 
sies en konsekwensies van húlle geloof gesien het, naamlik byna op libertinistiese wyse. Swak in die geloof verwys hier dus nie na 'n gebrekkige fides qua nie.

Filippense 1:25 (eis tēn humōn prokopēn kai charan tēs pisteös)

Soos bekend, gee Paulus in hierdie perikoop uitdrukking aan sy twyfel of hy moet kies om te sterwe en by die Here te wees of moet kies om te bly lewe. Hy weet dat om te sterwe en by die Here te wees vir hom verkiesliker is, maar nie vir die belange van die gemeente van Filippi nie. Dit oortuig hom dat die Here hom nog in die lewe sal laat bly tot voordeel van die gemeente. Die voordeel wat dit vir die gemeente sal hê, word dan uitgedruk deur bogenoemde frase. Uit vertalings en kommentare blyk dit duidelik dat ons ook hier te doen het met 'n frase waaroor die menings aansienlik uiteenloop. Spreek die apostel hier die oortuiging uit dat sy teenwoordigheid by die gemeente die geloof van die gemeente sal laat toeneem? By die interpretasie van hierdie frase hang alles daarvan af of aanvaar moet word dat die genitief tēs pisteös slegs die onmiddellik voorafgaande charan regeer of beide charan en prokopēn. Word eersgenoemde gekies (so byvoorbeeld Die Gute Nachricht; New English Bible; Philipps; Klijn 1969: 34; Lohmeyer 1964: 67) beteken dit dat die teenwoordigheid van die apostel vir die gemeente in tweërlei opsig voordeel sal inhou: dit sal bydra tot hulle voortgang en tot hulle vreugde in die geloof. Word vir laasgenoemde moontlikheid gekies, is die gedagte natuurlik dat sy teenwoordigheid by die gemeente sal bydra tot die toename van hulle geloof en hulle vreugde (so byvoorbeeld NAV; Good News Bible en verskeie kommentare). Die saak laat hom nie maklik uitmaak nie. Dit is egter seker dat die interpretasie wat vir geloofstoename kies, in geen opsig die enigste aanvaarbare blyk te wees nie.

'n Mens sou aan die ander kant kon vra waaruit die prokopē sou bestaan as dit op die gemeente as sodanig betrekking sou hê en nie op hulle geloof nie. In 1:12 is prokopē gebruik met verwysing na die voortgang of bevordering van die evangelie. Wat die gebruik van die woord in 1:25 betref, som Lohmeyer (1964: 67) die saak soos volg op: 'Fortschreiten bedeutet dann, von dem Wege des Martyriums sich nicht abdrängen lassen, sondern in innerer und äusserer Festigkeit ihn zu Ende gehen.' In die gedeelte wat vanaf vers 27 volg, word die gemeente opgeroep om as ' $n$ eenheid saam te stry vir die geloof in die evangelie en hulle nie deur die teenstanders te laat afskrik nie (28). Hulle word ook daarop gewys dat die voorreg om Christus te dien, nie net daarin 
bestaan om in Hom te glo nie, maar ook om vir Hom te ly (29). In die lig hiervan lyk dit volkome aanneemlik dat die prokopē van die gemeente verwys na hulle vasstaan in die geloof en hulle onverskrokke voortgang op die pad van die evangelie te midde van 'n vervolgingsituasie.

'n Ander, heeltemal aanneemlike verklaring word deur Matter (1965: 36) aangebied. Hy beskou die frase as 'lichtelijk' herbraïserend en meen dat dit daarom nie paratakties, nie maar hupotakties vertaal moet word met: 'de bevordering van de vreugde van uw geloof'.

Die saak is wat hierdie teks betref, om die minste te sê, só onseker dat dit kwalik gebruik kan word as bewys dat Paulus geloof gesien het as iets wat kon groei of toeneem.

\section{Tessalonisense 3:10 (katartisai ta husterēmata tēs pisteōs humōn)}

In hierdie vers vertel Paulus die gemeente van Tessalonika hoe onophoudelik en ernstig hy God bid om hulle weer persoonlik te mag sien en om so te kan aanvul wat nog aan hulle geloof ontbreek. Wat is dit wat ontbreek? Dui husterēmata daarop dat die geloof van die gemeente aan iets mank gaan, dat dit dus in een of ander opsig gebrekkig is? Indien wel, val dit vreemd op in die lig van die feit dat geeneen van die Pauliniese gemeentes so vir hulle geloof geprys word as juis hierdie gemeente nie (kyk byvoorbeeld 1:3, 7, 8; 2:19). Dit is wel waar dat Paulus besorg was dat die gemeente dalk vanweë vervolgings of deur verleiding weer sou terugval in ongeloof $(3: 3,5)$. Maar Timoteus het juis van die teendeel kom berig gee. Hy het kom vertel van hulle geloof en liefde (2:6) en dat hulle in die Here vas staan (2:8). Sou Paulus in die lig hiervan nog gereken het dat daar iets aan die kwaliteit of die egtheid van hulle geloof ontbreek het? Dit is uiters moeilik om te glo.

Dit is betekenisvol dat Ellingworth \& Nida (1975: 64) hier die volgende waarskuwing rig: 'In translation, it is better to avoid any expression which suggests that Paul is blaming the Thessalonians for having a faith which is less than fully mature.' Maar as die fides qua van die gemeente dan nie onder verdenking was nie, waarna verwys husterēmata dan? Die enigste aanneemlike verklaring sou wees dat dit dinge in gedagte het wat nog aan die gemeente se fides quae ontbreek het, dinge wat die apostel nog sou wou toevoeg by wat hy reeds aan hulle verkondig het (so gedeeltelik ook Best 1972: 145). Hierdie opvatting strook volledig met die gebruik van husterēma in 2 Korintiërs 9:12 met betrekking tot die gelowiges in Judea. Die gawes wat Paulus vir hierdie gelowiges ingesamel het, sou voorsien in waaraan hulle 'n behoefte gehad het (prosanaplērousa ta husterēmata tön hagiōn). Ook hier verwys 
husterèmata dus na die dinge waaraan daar 'n gebrek of behoefte was. Wilckens (1969: 597-598) is daarom gelyk te gee, wanneer hy sê: 'Dem üblichen neutestamentlichen Sprachgebrauch zufolge ist mit dem Genitiv tès pisteōs humōn nicht ein Mangel an Glauben, sondern ein Mangel, der für den Glauben als solchen in der Zeit vor dem Ende besteht, gemeint. Was dem Glauben fehlt, sind Verkündigung, Lehre und Paraklese durch den Apostel und Wegweisung durch Gott und den Kyrios selbst' (so ook min of meer Staab 1969: 24).

Al wat ek natuurlik hiermee probeer beredeneer het, is dat Paulus kwalik met hierdie woorde kon bedoel het dat die geloof van die gemeente van Tessalonika gebrekkig was. Hierdie bevinding hoef dus nog glad nie die moontlikheid uit te sluit dat Paulus wel van oordeel was dat geloof kon groei of verskillende grade van intensiteit kon vertoon nie. Dit bring ons by die laaste geval wat ondersoek moet word.

\section{Korintiërs 10:15 (elpida de echontes auxanomenès tès pisteōs humōn)}

Daar is by die meeste eksegete geen twyfel dat hier sprake is van indiyiduele geloofsgroei nie. 'n Uitsonderingsposisie word ingeneem deur Grosheide (1959: 296) wat pistis hier wel as fides qua verstaan, maar van mening is dat dit hier gaan om Paulus se vooruitsig dat meer mense in Korinte tot geloof sal kom. Die frase staan taamlik neutraal in 'n gedeelte waarin Paulus homself verdedig teenoor ander wat klaarblyklik sy aansprake in twyfel getrek het. Hy wys die gemeente daarop dat hy nie roem op wat buite die perke van sy opdrag of werksterrein lê nie (10:13). Die gemeente van Korinte lê binne die perke van sy opdrag. Deur op hulle te roem, gaan hy dus nie die perke te buite nie, want dit is nie ander mense se werk waarop hy roem nie (10:15). Dan spreek hy die hoop uit dat die geloof van die gemeente sal toeneem sodat hy dan onder hulle nog meer kan hê om op te roem. Die toename in die geloof van die gemeente sal derhalwe sy saak nog sterker maak en wat meer is, dit sal hom in staat stel om die evangelie ook nog in die streke anderkant hulle te verkondig (10:16).

Die gemeente word hier dus nie verwyt dat hulle geloof gebrekkig of onvolwasse is nie. ' $n$ Verdere toename daarin sal egter die apostel se saak sterk en die evangelie verder kan laat uitbrei. In watter opsig hierdie groei of toename moes plaasvind, is natuurlik nie uit die konteks vasstelbaar nie. Ons is bewus daarvan dat daar in die gemeente van Korinte allerlei probleme, wanopvattings en misstande was. Die tweede brief getuig ook van ernstige verhoudingsprobleme tussen 
Paulus en die gemeente en dat sy aandele by die gemeente op 'n stadium betreklik laag was. Wou Paulus met hierdie woorde die gemeente probeer beweeg tot ' $n$ bepaalde geloofsvolwassenheid wat ' $n$ einde sou maak aan die onenighede en gebrek aan die regte insig en gepaste gesindheid? Dit was hoogs waarskynlik die bedoeling. Dit sou dan wel ' $n$ sekere groei en ontwikkeling tot vastigheid in hulle geloofshouding en benadering veronderstel. 'n Mens sou uit die omstandigheidsgetuienis met reg kon sê dat so iets by die Korintiërs nodig was.

Wat het ons nou uit hierdie paar tekste wys geword met betrekking tot die vraag wat aan die orde is? Ons het tot die slotsom gekom dat, behalwe vir 2 Korintiërs 10:15, daar in hierdie gedeeltes weinig of geen sprake is van geloofsgroei nie. Indien hierdie interpretasie korrek is, laat dit dan nie meer vrae na vore kom as wat beantwoord kan word nie? Moet ons aanvaar dat na Paulus se beskouing, alle mense met ewe veel oorgawe en 'n ewe sterk oortuiging glo? As dit so is dat geloof elemente soos kennis, gehoorsaamheid, ontsag, oorgawe, vertroue, hoop, liefde en diens bevat, kan daar dan sonder meer aanvaar word dat alle gelowiges, jonk en oud, toegewyd en minder toegewyd, dieselfde geloof kan hê? Is die geloofslewe nie 'n proses waarin daar 'n voortdurende toename behoort te wees in die elemente hierbo genoem nie? En selfs al aanvaar ons dat geloof in die grond van die saak 'n gawe van God is, moet ons ook aanvaar dat dit in gelyke mate aan almal geskenk word of dat almal hierdie gawe met ewe veel entoesiasme aangryp en met ewe veel vrug daarvan gebruik maak? Sal Paulus dit tog toegee dat geloof in wese ' $n$ groeiende verskynsel is en is dit nie inderdaad so dat hy op allerlei wyses tog laat blyk dat hy hierdie standpunt deel nie?

Ons probleem by die beantwoording van al hierdie vrae is dat Paulus nie vir ons 'n sistematies uitgewerkte leer oor geloof nagelaat het nie. Wat hy wel te sê gehad het, moet ons aflei uit geleentheidsgeskrifte wat op bepaalde situasies gerig was en tot op groot hoogte deur die situasies bepaal was. Dit beteken natuurlik nie dat wat hy wel te sê gehad het wanneer hy 'n situasie aangespreek het, slegs van kontigente betekenis is of hoef te wees nie. 'n Mens kan egter nie help om jou in hierdie verband ' $n$ uitspraak van Boers (1982: 10) in herinnering te roep nie '... Paul's writings are not products of theological reflection, and thus cannot be interpreted theologically. There is no such thing as a theology of Paul, although many New Testament scholars have written "theologies" based on Paul. The letters individually and as a group do 
not have theological integrity. They are written from fundamental religious/pastoral concerns.' Indien hierdie waarneming korrek is, hou dit in dat wanneer Paulus wel by geleentheid teenoor ' $n$ gemeente die opmerking gemaak het dat hulle geloof moet toeneem, dit nog nie hoef te beteken dat hy geloof prinsipieel gesien het as 'n entiteit wat fases deurmaak of in grade van intensiteit kan bestaan nie. Aan die ander kant wil dit natuurlik ook nie sê dat hy 'n standpunt wat hy met betrekking tot ' $n$ bepaalde situasie gehuldig het, nie ook in ander omstandighede sou handhaaf nie.

Vir sover 'n mens wel na Paulus se beskouing oor geloof kan vra, sal dit nie mag geskied buite die indikatief-imperatief-dialektiek om, wat by hom so prominent figureer nie. Nie alleen het die heilsindikatief 'n radikaal nuwe bestaansmoontlikheid in Christus geskep nie, dit is ook die enigste grond en motief vir die imperatief (kyk bv Rom 6-8; 2 Kor $5: 14 \mathrm{vv}$; Gal 3:26 vv; 6:15). Terwyl hierdie nuwe lewe in Christus reeds objektief 'n werklikheid is, moet dit deur geloof vir die gelowige ook'n subjektiewe werklikheid word. In antwoord op die imperatief moet hy dit tot sy eie maak. So radikaal as wat die indikatief is, so radikaal is die eis van die imperatief. ' $n$ Mens kry nêrens die indruk dat die Pauliniese imperatief om minder vra as geloof in die volste sin van die woord nie, wat geloof in die volste sin ook al mag behels. ' $n$ Mens kry ook nie die indruk dat hierdie imperatief om iets minder vra as geloofsbeslissing hier en nou nie, en dat dit op minder aanspraak maak as die totale mens en dit op alle terreine van sy lewe nie.

Dat nie alle mense op die evangelie en die oproep tot geloof met totale oorgawe reageer nie, kan nie aan die wese van die geloof toegeskryf word nie. Ons moet 'n onderskeid maak tussen wat in die praktyk gebeur en wat geloof in wese is. Dit is ondenkbaar dat Paulus na aanleiding van die praktyk sy beskouing oor die wese van geloof sou vorm of wysig. Dit wil inderdaad lyk of hy aan geloof wesenlik iets meer toegeken het as bloot menslike reaksie op die evangelie. Dit is gewis vir hom gawe van God, al sê hy dit meer by implikasie as dat hy dit uitdruklik stel. En as gawe word dit tog seker ten volle gegee. Benewens die gawe karakter daarvan kry 'n mens by hom ook die indruk dat geloof as entiteit die mens transendeer, dat dit in 'n sekere sin die mens vóór is. Hoewel dit by elke individuele mens persoonlike geskiedenis word, is dit ook éérs en in die eerste plek in die gemeente daar. Dit gaan die individuele gelowige se geloof dus ook hiér vooraf.

Paulus het sekerlik ' $n$ vordering in die lewe in die geloof by elke gelowige veronderstel; daarop is die imperatief immers afgestem. Maar 
dit bly steeds ' $n$ radikale eis vir elke dag. Dit bly 'n elke-dag-se-eis om jou lewe in ooreenstemming te bring met die geloof wat jy bely. Die geloof wat jy bely, kan nie afhanklik gemaak word van die lewe wat jy lei nie. Nee die lewe wat jy lei, moet in ooreenstemming wees met die geloof wat jy bely. En die geloof wat jy bely, kan nie ' $n$ swak of middelmatige of sterk geloof wees nie. Dit kan nie ingeboude reserwes hê nie, dit kan alleen geloof wees. 'n Mens word nie deur een of ander vòrm van geloof salig nie, ' $n$ mens word deur geloof salig.

As ' $n$ mens eenmaal daartoe oorgaan om geloof iets minder te maak as wat dit is, as jy dit eenmaal oorgelaat het aan die lot van die menslike lewenspraktyk, het jy dit sy karakter ontneem en dit prakties op die langebaan geskuif. Dit lyk nie of Paulus hom in prinsipe hiermee sou kon versoen nie, want hiermee ontneem die gelowige homself die voorreg om hier en nou die nuwe mens te wees wat hy in Christus is. Selfs al sou ons by herhaling moes stel dat die praktyk geen bewys lewer van so ' $n$ radikale nuutheid nie, mag dit ons nog steeds nie verlei om van geloof ' $n$ groeiproses te wil maak nie. Dit ontneem ons die verantwoordelikheid vir geloofsbeslissing elke dag, en telkens ten spyte van wat ons in die praktyk ervaar.

Word dit nie maar weer ' $n$ nuwe slawejuk, 'n wettisisme, 'n perfeksionistiese droom nie? As ek Paulus reg verstaan, sê hy juis dat hierdie nuwe bedeling wat deur die Gees beheers word, vir die gelowige nie opnuut slawerny nie, maar vryheid beteken (Rom 8:2,15). En lewe in verbondenheid met Christus kan geen perfeksionisme wees nie, dit is gewoon lewe in die regte verhouding met God. Daarom geld Paulus se oproep onverswak: Ons lewe deur die Gees; laat die Gees nou ook ons gedrag bepaal (Gal 5:25). Wie oor geloof dink, moet so daaroor dink. Hy moet sy handel en wandel daagliks ten volle gestel sien voor die radikale eis van die imperatief. As hy in geloof iets van die indikatief begryp en ervaar het, sal die imperatief vir hom ' $n$ vanselfsprekendheid wees.

Hiermee is die laaste woord oor die aangeleentheid sekerlik nog nie gespreek nie. Hierdie studie word nogtans aangebied vir moontlike verdere diskussie oor die saak as mede ter nagedagtenis aan die hooggeleerde, internasionaal-erkende wyle A van Selms. Van hom het almal wat aan sy voete gesit het, nie alleen baie geleer nie, maar vir sy kennis en hoogstaande akademiese bekwaamheid kan ' $n$ mens alleen maar die hoogste agting hê. Die indruk wat hy op 'n mens gemaak het, sal onvergeetlik bly. 


\section{Literatuurverwysings}

ALTHAUS, P 1970. Der Brief an die Römer. 11. Auflage. Göttingen: Vandenhoeck. (NTD). BARRET, CK 1977. The epistle to the Romans. London: Black. (Black's NT comm).

BEST, E 1972. The first and second epistles to the Thessalonians. London: Black. (Black's NT Comm).

BINDER, H 1968. Der Glaube bei Paulus. Berlin: Evangelische Verlag.

BOERS, $H$ 1982. The problem of Jews and gentiles in the macro-structure of Romans. Neotestamentica 15, 1-11. (New Testament Society of SA).

BULTMANN, R 1965. Erziehung und christlicher Glaube. Glauben und Verstehen IV. Tübingen: Mohr.

BULTMANN, R 1968. Theologie des Neuen Testaments. 6. Auflage. Tübingen: Mohr.

CONZELMANN, H 1968. Grundriss der Theologie des Neuen Testaments. 2. Auflage. München: Kaiser.

CRANFIELD, CEB 1962. Metron pisteōs in Rom XII, 3. NTS 8, 345-51.

ELLINGWORTH, P \& EA NIDA, 1975. A translator's handbook on Paul's letters to the Thessalonians. Stuttgart: UBS. (Helps for translators).

FRIEDRICH, G 1982. Glaube und Verkündigung bei Paulus, in Hahn, F \& $H$ Klein (Hrsg). Glaube im Neuen Testament. Neukirchen: Neukirchener Verlag. (Biblisch theologische Studien).

GROSHEIDE, FW 1959. De tweede brief aan die kerk te Korinthe. 2de uitgawe. Kampen: Kok. (Comm op het NT).

KÄSEMANN, E 1974. An die Römer. 2. Auflage. Tübingen: Mohr (Handb z NT).

KLIJN, AFJ 1969. De brief van Paulus aan de Filippenzen. Nijkerk : Callenbach. (De predik van het NT).

LOHMEYER, E 1929. Grundlagen paulinisher Theologie. Tübingen. (BHTh I).

LOHMEYER, E 1964. Die Briefe an die Philipper, Kolosser und an Philemon. Göttingen: Vandenhoeck. (Kritisch-exeg Komm).

MATTER, HM 1965. De brief aan de Philippenzen en de brief aan Philemon. Kampen: Kok. (Comm op het NT).

MICHEL, O 1963. Der Brief an die Römer. 12. Auflage. Göttingen: Vandenhoeck. (Kritischexeg komm $z$ NT).

NEUGEBAUER, F 1961. In Christus. Göttingen: Vandenhoeck.

RIDDERBOS, H 1959. Aan de Romeinen. Kampen: Kok (Comm op het NT).

SCHLIER, H 1979. Der Romerbrief. Zweite Auflage. Freiburg: Herder. (Herders theol komm z NT).

STAAB, K 1969. Die Thessalonicherbriefe. Die Gefangenschaftsbriefe. 5. Auflage. Regensburg: Pustet. (Regensburger NT).

WILCKENS, U 1969. Husterèma, in Friedrich, G (Hrsg). ThWNT VIll. Stuttgart: Kohlhammer.

WILCKENS, U 1982. Der Brief an die Römer 3. Zürich: Benziger. (EKK). 